as an RMO, I cannot see that, providing one exercises the ordinary social decencies, what difference it makes how one is attired, tie or no tie, pin stripe suit or jeans.

Within the limits of recognition of the seriousness of the situation in which the civil liberty of a person is at stake, and the maintenance of a disciplined structure, allowing each party adequately to state his or her case, I would favour from my two vantage points as informal procedure as possible. The more the President - who must set the tone of the proceedings - can reassure the patient and his or her relatives that the prime function of the Tribunal is to safeguard the welfare of the patient (and of course other persons) and that nobody is "on trial", the better it will be for all concerned. What one wears on these occasions is, I submit, a matter of supreme irrelevance.

Despite Dr Heaton-Ward's criticisms of RMOs who find difficulty in attending hearings because of pre-arranged out-patient or other appointments, as a busy RMO myself, I have great sympathy with them and it seems only reasonable for the Tribunal to allow a deputy to give evidence or require a relatively brief attendance. I do agree with Dr Hunter that the College should do all in its power to encourage a high standard of reporting to tribunals by RMOs, and I think that this would be best achieved in the long run by making attendance, and perhaps giving evidence at Tribunals, part of a junior doctor's training. What I find truly embarrassing as a medical member is to hear a RMO give evidence when he or she has not made an adequate examination of the patient.

Whittington Hospital

J. J. BRADLEY

London N19

\section{Treatment of psychotic patients in prison}

DeAR Sirs

Dr Herridge reminds us of a situation in the prisons which would be intolerable in a modern psychiatric unit and yet has become accepted as the norm in our prison hospitals (Psychiatric Bulletin, April 1989).

The Mental Health Act as an instrument for authorising treatment does not apply in the prisons; not even if the prisoner has been sectioned and is awaiting transfer to hospital. If the Act were to be altered and the provisions extended to cover the treatment of psychotic patients in prison then the Mental Health Act Commission would have to have access to the prison hospital.

Dr Herridge suggests a three day treatment order, presumably equivalent to Section 4; but that would preclude the giving of long-acting medication and also the adequate treatment of the deluded and potentially violent schizophrenic patient. There would have to be at least provision for a 28 day treatment order and the consequence of that would be the right to apply to a Mental Health Tribunal sitting in a large busy prison hospital, which makes the mind boggle.

The right way to proceed is by the use of common law and Section 48. I do common law certificates in our local prisons from time to time. I rely on the doctrine of necessity and the spirit of Section 62(d) of the Mental Health Act.

I would quote Larry Gostin who says, "the doctrine of necessity might be construed more liberally to embrace treatment or restraint administered in the course of an emergency. For example, a tranquilliser injected to calm a patient during a violent episode". I and the prison medical officers have yet to be sued for not acting in good faith.

Section 48 is the right way to proceed. Once the certificates are completed, it can be a phone-in procedure which will be arranged in a few hours with the Home Office. One needs a friendly forensic psychiatrist and an unsilted secure unit. The former are arranged by the forensic psychiatrists having weekly sessional commitments to the local prisons and the latter by the profession finally deciding about the nature of the residual psychiatric hospital, and its need to include a well thought out Unit for the treatment of process schizophrenia, perhaps at the supra district level.

Dr Herridge gives us food for thought. The HAS cannot be expected to visit the local doss house or wander around under the arches at night with Dr Weller; but it is surely time that the HAS accepted that their very important contributions would have greater credibility if they incorporated visits to the local prisons before putting pen to paper about the excellence, or otherwise, of local psychiatric services.

R. W. K. REEVES

Glenside Hospital

Blackberry Hill

Stapleton, Bristol

\section{Reference}

Gostin, L. (1983) A Practical Guide to Mental Health Law. London: MIND (National Association for Mental Health)

Escapes from Bedlam and lunar phase: failure to confirm the lunacy theory

\section{DeAR SIRS}

Despite an extensive confounding literature (Rotton \& Kelly, 1985; Campbell \& Beets, 1978), belief that 
the moon's phase affects behaviour remains a persistent superstition. Recent studies (Little et al, 1987; Durm et al, 1986) have failed to demonstrate any relationship between lunar phase and disruptive behaviour in mental hospitals. It has been argued that historically, when such beliefs were most prevalent, the moon may have had a greater effect on behaviour, since in the absence of domestic and street lighting, its significance as a photic stimulus would have been greater (Campbell \& Beets, 1978). No published studies have included data from such historical periods.

Using escapes from Bethlem Hospital between 1690 and 1790 as episodes of disruptive behaviour among confined 'lunatics', I examined the relationship between them and lunar phase. Examination of the registers of admission to the curable wards at Bethlem between 1690 and 1790 revealed 120 escapes whose data were recorded. Wherever possible, minutes of the meetings of the Court of Governors of Bethlem and Bridewell were used to confirm dates of individual escapes. Using tables of new and full moons for the period, each of the escapes was allocated to a particular day of the synodic lunar cycle (the period between full moons; 29.5 days). The distribution of escape frequency throughout the lunar cycle was tested for departure from randomness using the Pearson Chi-squared test. There was no significant relationship between escape and phase of the moon, escapes were distributed randomly throughout the lunar cycle. Bethlem Hospital at this time, despite major structural imperfections in the building and its walls, was a secure establishment from which escape was a rare and difficult event.

Contemporary studies of psychiatric hospital absconders have shown that they are predominantly male, young, compulsorily admitted, and have a discharge diagnosis of schizophrenia (Tomison, 1989). Successful 18th century escapees might then, as today, have been some of the most disturbed patients; their escape dates thus pinpointing periods of acute lunacy. Escape might also have been an indirect index of psychiatric disturbance: while the mad-house keepers were occupied restraining the most disturbed, the way might be clearer for others to make their escape. John Haslam noted in 1809: "It is an odd opinion and continues still to prevail, that maniacs are influenced by the changes of the moon". Haslam was keen to debunk the notion of planetary regency, and kept himself, for a period of two years, a register of behaviour of patients at Bethlem from which he found no evidence of lunar influence. He reported that, rather than the inmates, it was staff who were: "so much under the dominion of this planet ... that, without waiting for any display of increased turbulence on the part of the patient, he had bound, chained, flogged, and deprived these miserable people of food, according as he discovered the moon's age by the almanack" (Haslam, 1809). It is depressing to discover that almost a century and a half later, in 1936, a visitor to an insane asylum in the West Indies was told by one of the guards that the patients were easy to handle, except at the time of the full moon "when special precautions have to be taken in order to restrain them" (Oliven, 1943). Indeed, lunar beliefs still remain prevalent among those caring for the mentally ill; $74 \%$ of nurses working in one psychiatric setting believed that the moon affects mental illness (Rotton \& Kelly, 1985). Continued widespread belief in the effect of the moon on psychiatric patients shows the potency of prejudice and ill-founded beliefs in their care.

\section{The Bethlem Royal Hospital}

Beckenham, Kent

\section{References}

Campbell, D. E. \& Beets, J. L. (1978) Lunacy and the moon. Psychological Bulletin, 85, 1123-1129.

DURM, M. W., TERRY, C. L. \& HAMMONDS, C. R. (1986) Lunar phase and acting-out behaviour. Psychological Reports, 59, 987-990.

HASLAM, J. (1809) Observations on Madness and Melancholy: including practical remarks on those diseases; together with cases: and an account of the morbid appearance on dissection. 2nd edition, considerably enlarged. London: J. Callow.

LITTLE, G. L., BOWERS, R. \& LITTLE, L. (1987) Geophysical variables and behavior: XLII. Lack of relationship between moon phase and incidents of disruptive behavior in inmates with psychiatric problems. Perceptual and Motor Skills, 64, 1212.

Oliven, J. F. (1943) Moonlight and nervous disorders: A historical study. American Journal of Psychiatry, 99, 579-584.

Rotron, J. \& Kelly, I. W. (1985). Much ado about the full moon: a meta-analysis of lunar lunacy research. (Psychological Bulletin, 97, 286-306.

Tomison, A. R. (1989). Characteristics of psychiatric hospital absconders. British Journal of Psychiatry, 154, 368-371.

\section{Admission decisions in an adolescent unit}

\section{DeAr Sirs}

Inter-agency functioning is highlighted by the account of the professionals' difficulty around a suicide-threatening adolescent in a Manchester headteacher's office given by Dr Sutton and by the comments of Drs Modell and Kaplan, and Messrs 